\title{
IMMUNOPATHOLOGIC EFFECTS ASSOCIATED WITH SARCOCYSTIS NEURONA-INFECTED INTERFERON-GAMMA KNOCKOUT MICE
}

\author{
Author(s): Sharon G. Witonsky, Robert M. Gogal Jr. , Robert B. Duncan , and David S. Lindsay
}

Source: Journal of Parasitology, 89(5):932-940. 2003.

Published By: American Society of Parasitologists

DOI: http://dx.doi.org/10.1645/GE-72R

URL: http://www.bioone.org/doi/full/10.1645/GE-72R

BioOne (www.bioone.org) is a nonprofit, online aggregation of core research in the biological, ecological, and environmental sciences. BioOne provides a sustainable online platform for over 170 journals and books published by nonprofit societies, associations, museums, institutions, and presses.

Your use of this PDF, the BioOne Web site, and all posted and associated content indicates your acceptance of BioOne's Terms of Use, available at www.bioone.org/page/terms_of_use.

Usage of BioOne content is strictly limited to personal, educational, and non-commercial use. Commercial inquiries or rights and permissions requests should be directed to the individual publisher as copyright holder. 


\title{
IMMUNOPATHOLOGIC EFFECTS ASSOCIATED WITH SARCOCYSTIS NEURONA-INFECTED INTERFERON-GAMMA KNOCKOUT MICE
}

\author{
Sharon G. Witonsky, Robert M. Gogal, Jr.*, Robert B. Duncan†, and David S. Lindsay ${ }^{\star}$ \\ Department of Large Animal Clinical Sciences, Virginia-Maryland Regional College of Veterinary Medicine, Virginia Polytechnic Institute and \\ State University (Virginia Tech), Blacksburg, VA 24061-0442. e-mail: switonsk@vt.edu
}

\begin{abstract}
Interferon-gamma knockout (IFN-gamma KO) mice were infected with Sarcocystis neurona merozoites to characterize the immunopathology associated with infection. By day 14 postinfection (PI), mice developed splenomegaly and lymphadenopathy, characterized by marked lymphoid hyperplasia with increased numbers of germinal centers. Additional histopathologic changes included increased extramedullary hematopoiesis, multifocal mixed inflammatory infiltrates in the liver, perivascular infiltrate of the liver and lung, and interstitial pneumonia. The total number of B-cell splenocytes $(P<0.05)$ and the percentage of B-cells increased on day 14 PI in the spleen and on day 28 PI in the lymph nodes $(P<0.05)$. By day 28 PI, the number of B-cell splenocytes decreased significantly. A non-subset-specific decrease in percentages of CD4 lymphocytes throughout all lymphoid organs was observed on day 14 PI. However, total CD4 and CD44/CD4 splenocytes increased significantly by day 28 PI. Early-activation CD8 lymphocytes were reduced in the blood and spleen, whereas memory CD8 lymphocyte percentages and total numbers were significantly increased. On the basis of the results, we propose that $S$. neurona-infected IFN-gamma KO mice are immunocompromised and unable to clear the infection. Thus, they develop B-cell exhaustion and a delayed, but sustained, increased number of memory CD4 and CD8 lymphocytes due to chronic antigen stimulation.
\end{abstract}

Sarcocystis neurona is the predominant causative agent of equine protozoal myeloencephalitis. Despite a national seroprevalence of $50 \%$, with some areas of the country being $70-$ $80 \%$ positive, only $1 \%$ of all horses are clinically affected (MacKay 1997; Saville et al., 1997). This suggests that in most horses, normal immune function prevents clinical disease. In fact, many attempts to develop a repeatable equine model have been unsuccessful (Fenger et al., 1997; Cutler et al., 2001; Saville et al., 2001), most likely because of effective host immune response preventing clinical disease. Some researchers have attempted to develop mouse models that exhibit neurologic disease; however, only immunodeficient mice (Marsh et al., 1997; Lindsay and Dubey, 1999; Fritz and Dubey, 2002) appear to succumb to infection. Nude mice, which lack normal T- and Blymphocytes, have been used to determine the pathogen life cycle (Marsh et al., 1997). However, because they have a severely compromised dysfunctional immune system, the model cannot be used for assessing therapeutic response or normal host immune response to infection. Interferon-gamma (IFNgamma) gene knockout (KO) mice were established by Dubey and Lindsay (1998) as a model to study drug efficacy and the $S$. neurona life cycle. Depletion of IFN-gamma compromises both innate and adaptive responses. Although some components of the immune response are limited because of the lack of IFNgamma, particularly with respect to natural killer (NK) cell activity, macrophage activation, CD4 Th1 responses, and CD8 cytotoxicity, other responses may be normal or slightly reduced, i.e., humoral response, non-IFN-gamma-dependent nitric oxide response, etc. Rather than eliminating the host immune response, as with nude mice, the immunity of gamma-IFN KO mice may be delayed or reduced, which permits clinical disease to develop. Thus, the pathophysiologic and pathoimmunologic

Received 10 December 2002; revised 9 April 2003; accepted 24 April 2003.

* Center for Molecular Medicine and Infectious Disease, Department of Biomedical Sciences and Pathobiology, Virginia Polytechnic Institute and State University, 1410 Prices Fork Road, Blacksburg, Virginia 24061-0442.

$\dagger$ Department of Biomedical Sciences and Pathobiology, Virginia Polytechnic Institute and State University, Duck Pond Drive, Blacksburg, Virginia 24061-0442. mechanisms of the disease can still be determined. By understanding the host immune response to, and pathophysiologic mechanisms of, S. neurona infection, supportive immunotherapies and immunoprotective vaccines can be developed. For these reasons, IFN-gamma KO mice were infected with $S$. neurona to evaluate the pathophysiologic and immunopathologic mechanisms associated with infection. Gross and histopathologic changes were correlated with immune responses as assessed by seroconversion and quantitative changes in immune cell subsets.

\section{MATERIALS AND METHODS}

\section{Maintenance of Sarcocystis neurona cultures}

Sarcocystis neurona merozoites (SNOP-15) were grown and maintained in African green monkey (Cercopithecus aethiops) kidney cells (CV-1 cells, ATCC CCL-70, American Type Culture Collection, Manassas, Virginia) as previously described (Rosypal et al., 2002).

For mouse infections, merozoites were harvested from infected cell cultures by removing the medium and replacing it with Hanks balanced salt solution without calcium and magnesium. Host cells were then removed from the plastic growth surface with a cell scraper. This cell mixture was passed through a 27 -gauge needle attached to a $10-\mathrm{ml}$ syringe to disrupt the host cells. The suspension was passed through a sterile 3- $\mu \mathrm{m}$ filter to remove cellular debris. The number of merozoites in the filtrate was determined by using a hemacytometer (Lindsay and Dubey, 2001).

\section{Direct agglutination test for Sarcocystis neurona antibodies}

Detection of $S$. neurona-specific antibodies was accomplished as previously described by Lindsay and Dubey (2001). Positive controls consisted of previously collected serum from $S$. neurona-infected mice. Negative controls consisted of sera from $N$. caninum-positive mice, $T$. gondii-positive mice, and noninfected mice.

\section{Infection and examination of mice}

Breeding pairs of IFN-gamma KO mice were obtained from Charles River Laboratories, Inc., Wilmington, Massachusetts. Colonies were bred and maintained at the Virginia-Maryland Regional College of Veterinary Medicine Nonclient Lab Animal Facility, Blacksburg, Virginia. Mice were maintained in conventional housing and fed normal murine diet ad lib. Female mice at a minimum age of 4-6 wk were infected with $1 \times 10^{7}$ S. neurona merozoites s.c. Noninfected, age-matched mice served as controls. Blood was collected through the orbital sinus before death, and the blood was divided into nonheparinized and heparinized tubes for serum and flow cytometry, respectively. Mice were killed on days 14 and 28 postinfection (PI) with an overdose of halothane. All 
protocols were compliant with Virginia Tech Animal Care and Use Committee recommendations. For the experiments described here, data from 15 uninfected controls and 8 infected mice at each time point were used.

Mice were weighed at the time of death. Necropsies were performed, and spleens were weighed. Portions of thymus, spleen, lymph nodes (LN) (mesenteric, axillary, inguinal), kidney, liver, lung, and brain were collected and submitted for histopathology. Sections were fixed in $10 \%$ buffered neutral formalin and embedded in paraffin. Portions of spleen and LN were individually collected and placed in incomplete media for cell dissociation, enumeration, and flow cytometric analysis.

\section{Blood processing and serology}

Heparinized blood from each mouse was run individually. Samples were diluted a minimum of 1:4 in incomplete media (Roswell Park Memorial Institute [RPMI] 1640, Thompson Scientific, Swedesboro, New Jersey). The blood was layered at a maximum of 3:1 on One-Step (Accurate Chemical, New York, New York). Samples were spun at 700 $g$ for $25 \mathrm{~min}$ at room temperature $(23 \mathrm{C})$. The buffy coat was collected, and samples were washed 3 times in incomplete media $(250 \mathrm{~g}, 5 \mathrm{~min})$. Samples were then resuspended and analyzed by flow cytometry. (Tripp et al., 1997)

Serum from each mouse was tested individually for antibodies to $S$. neurona, using the agglutination assay (Lindsay and Dubey, 2001). Serum from uninfected mice $(n=6)$ and infected mice $(n=6)$ were pooled in groups of 2 samples per group and submitted to the Research Animal Diagnostic and Investigative Laboratory (RADIL) (Columbia, Missouri) for serological testing for Mycoplasma, Sendai virus, and murine hepatitis virus.

\section{Preparation of spleen and Iymph node samples}

Tissue samples were dissociated using a 3-ml plunger over a tissue sieve. Spleen samples were placed in a total volume of $10 \mathrm{ml}$ of incomplete media. Cells were enumerated using the Casy-1 Model TTC Cell Counter and Analyzer System (Sharfe System GMbH, Berlin, Germany). The cells were centrifuged at $250 \mathrm{~g}$ for $5 \mathrm{~min}$ and resuspended in a minimum volume for flow cytometry (Gogal et al., 2000).

\section{Flow cytometry}

For each sample, $5 \times 10^{5}$ cells were placed in a 96-well round-bottom plate. Cells were washed with phosphate-buffered saline (PBS) (250 g, 5 min). The cells were stained with either PE-B220/FITC-CD69 or FITC-CD62/PE-CD44/Tri-color CD8/Texas Red CD4 at a concentration of approximately $0.5 \mu \mathrm{g}$ of stain per $10^{6}$ cells. All antibodies were from Pharmingen (San Diego, California), except Tri-color CD8 and Texas Red-CD4, which were from Caltag (Burlingame, California). Samples were stained for $20 \mathrm{~min}$ at $4 \mathrm{C}$ and then washed with PBS (250 g, 5 min). Cells were resuspended in PBS and analyzed on the EPICS XL Flow Cytometer (Coulter, Hileah, Florida). A total of 10,000 lymphocytes were collected per sample (Tripp et al., 1997).

\section{Statistical analysis}

Analysis of variance was conducted using the GLM procedure of the SAS system (version 8.2, SAS Institute Inc., Cary, North Carolina) to test for treatment effects. Standardized residual plots were used to assess model adequacy. Mean separation was performed using Tukey's honestly significant difference test.

\section{RESULTS}

\section{Serology}

All infected animals underwent seroconversion by day 14 PI at a dilution of 1:50 of serum. Negative controls and uninfected mice had negative titers (data not shown). Serologic analysis for the presence of Mycoplasma, Sendai virus, and mouse hepatitis virus was negative for all groups.

\section{Gross examination and cellularity data}

By day 14 PI, infected mice developed splenomegaly, which was confirmed by significantly increased spleen-body weight ratios and significantly increased cellularity (Fig. 1). Splenomegaly persisted on day 28 PI. Although the weight and cellularity had decreased slightly by day $28 \mathrm{PI}$, numbers were still markedly $(P<0.05)$ elevated compared with uninfected controls. Bilateral symmetrical lymphadenopathy of the inguinal and axillary LN (ILN and ALN) was also present on both day 14 and day 28 PI. Mesenteric LN were also enlarged.

\section{Histopathologic analysis}

Spleens from $S$. neurona-infected mice had marked increases in follicular lymphoid hyperplasia with prominent germinal centers (Fig. 2A, B). Extramedullary hematopoiesis (EMH) was markedly increased in spleens harvested from infected mice on day 14 PI. By day 28 PI, germinal centers and lymphoid follicles had diminished moderately in size (Fig. 2C), but they were still larger than those from spleens from uninfected controls. EMH was persistently increased, such that about $50-60 \%$ of the spleen cross-sectional area was EMH, compared with $20-30 \%$ of the cross-sectional area of spleens harvested on day 14 PI.

LN had markedly increased numbers of secondary follicles and large germinal centers by day 14 PI (Fig. 2D, E). High endothelial venules were conspicuous, and sinusoidal macrophages and eosinophils were also present. By day $28 \mathrm{PI}$, the follicular and germinal center activity was diminishing, but it was still markedly greater than the controls. Other changes included plasma cell transformation of the medullary cords, neutrophils in the paracortex, and the conspicuous presence of histiocytes associated with the loss of lymphocytes and plasma cells. In some mice, the thymus of $S$. neurona-infected mice had cortical lymphoid depletion by day 28 PI compared with the controls.

Livers from infected mice contained sinusoidal foci of mixed inflammatory cells, predominantly lymphocytes and neutrophils (Fig. 3A, B). Infiltrates increased in size and number from day 14 to day 28 PI (Fig. 3C). Perivascular infiltrates, composed of lymphocytes and neutrophils, were as numerous as mixed inflammatory foci. The perivascular inflammation remained static or progressed mildly from day 14 to day 28 PI. Foci of EMH were also present but not extensive on day 14 PI.

Sarcocystis neurona-infected mice developed progressive mild to moderate multifocal interstitial pneumonia, similar to that previously described by Fritz and Dubey (2002). By day 28 PI, the majority of the $S$. neurona-infected mice had moderate amounts of interstitial pneumonia with perivascular infiltrates, which progressed from mild to moderate between days 14 and 28 PI.

Histopathologic analyses of brains from mice 28 day PI documented the development of encephalitis or meningioencephalitis, or both, as described previously by Fritz and Dubey (2002). The architecture of the meninges was obscured with focally extensive mixed infiltrates composed of eosinophils, neutrophils, and fewer lymphocytes. Inflammation was accompanied by vascular endothelial cell hypertrophy. In some cases, merozoites were visible. 


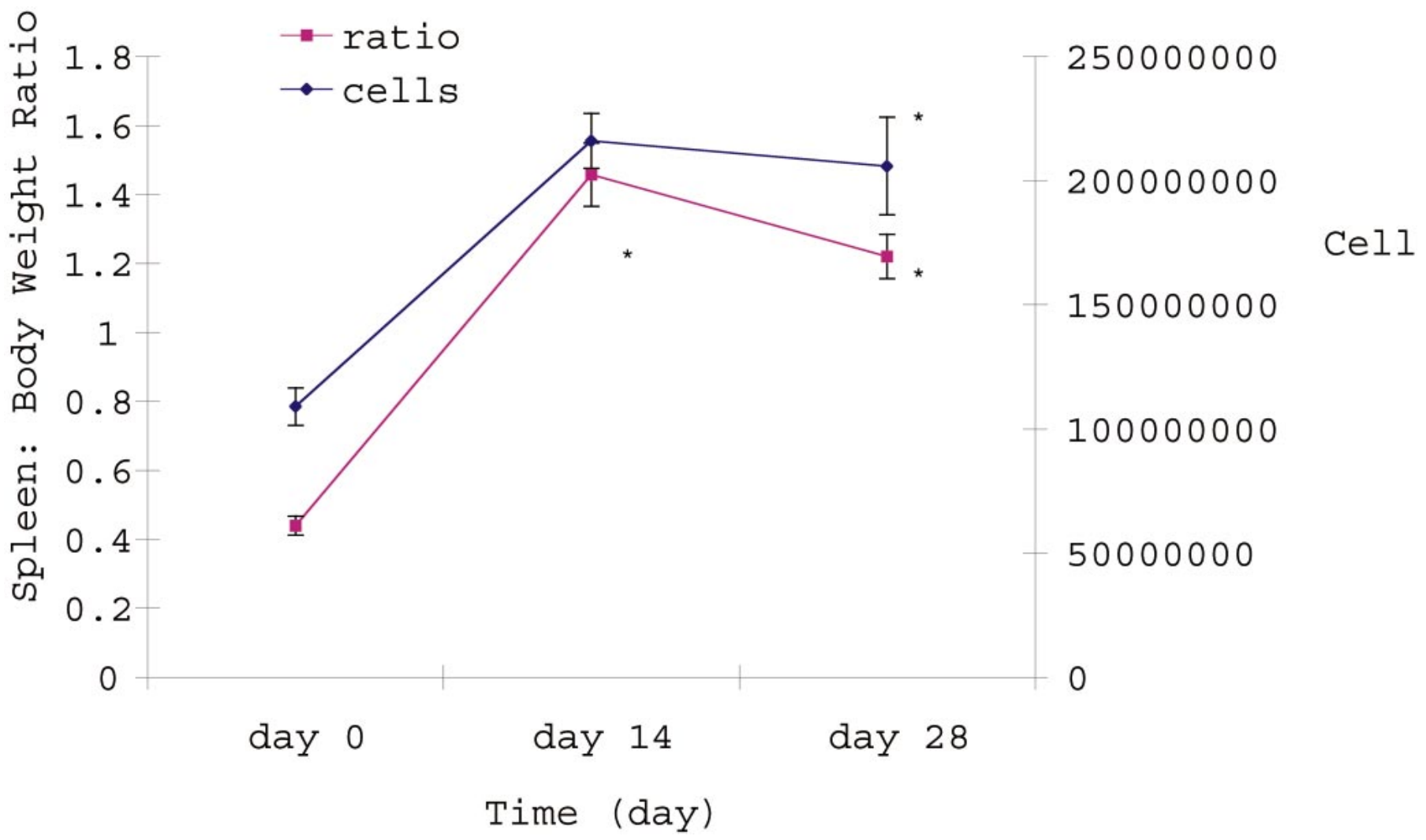

FIGURE 1. Changes in splenic weight and cellularity associated with infection in IFN-gamma KO mice $(* P<0.05)$.
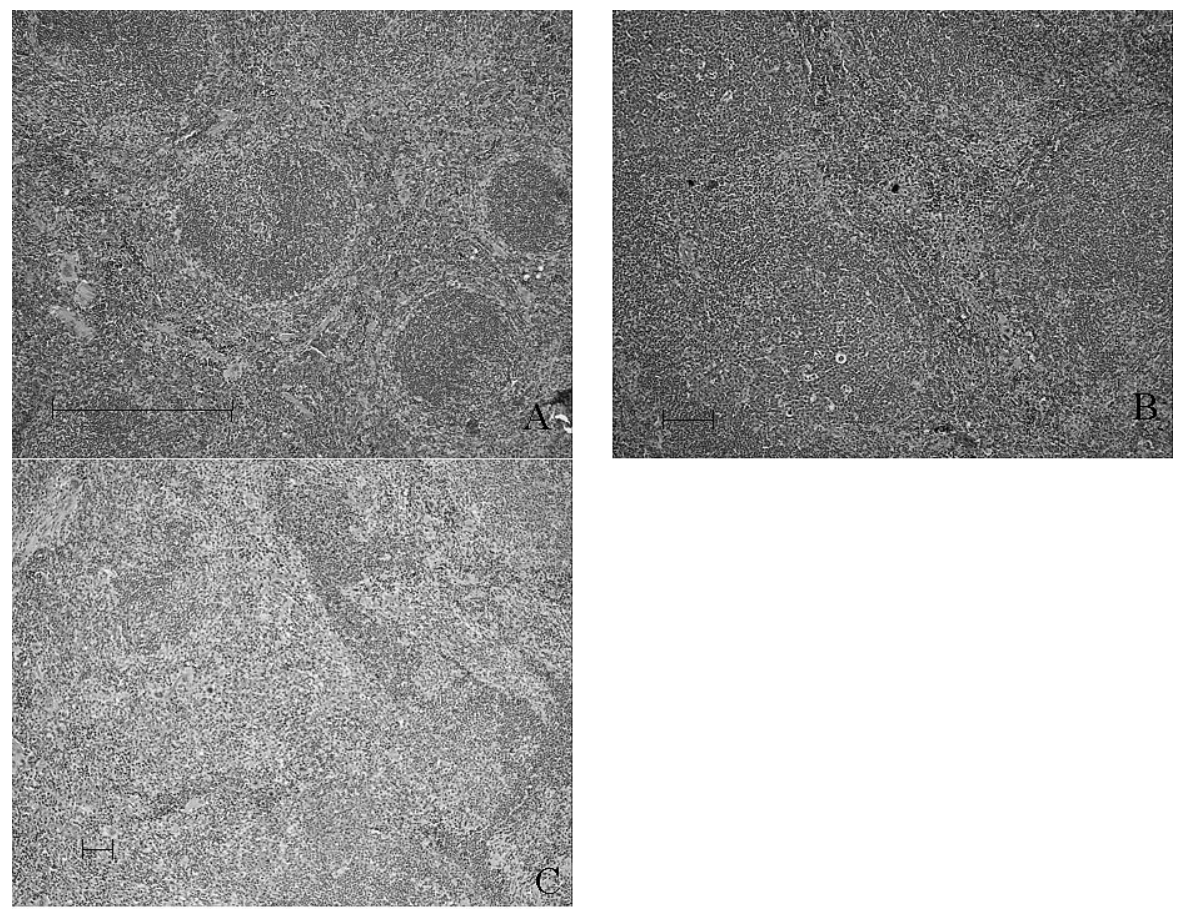

FIGURE 2. Histopathologic changes associated with Sarcocystis neurona infection in IFN-gamma KO mice. A. Spleen from uninfected control mouse. Bar $=420 \mu \mathrm{m}$. B. Spleen from day 14 PI IFN gamma KO mouse on day 14 PI. Bar $=90 \mu \mathrm{m}$. C. Spleen from day 28 PI IFN-gamma $\mathrm{KO}$ mouse. $\mathrm{Bar}=50 \mu \mathrm{m}$. 


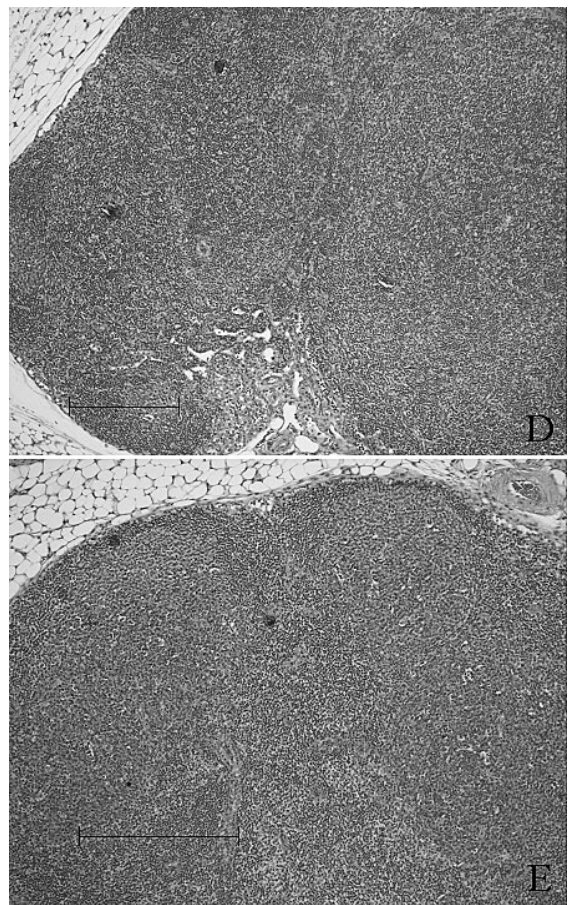

Figure 2. Continued. D. LN from uninfected IFN-gamma KO mouse. Bar $=270 \mu \mathrm{m}$. E. $\mathrm{LN}$ from day $14 \mathrm{PI}$ IFN-gamma KO mouse. $\operatorname{Bar}=350 \mu \mathrm{m}$.
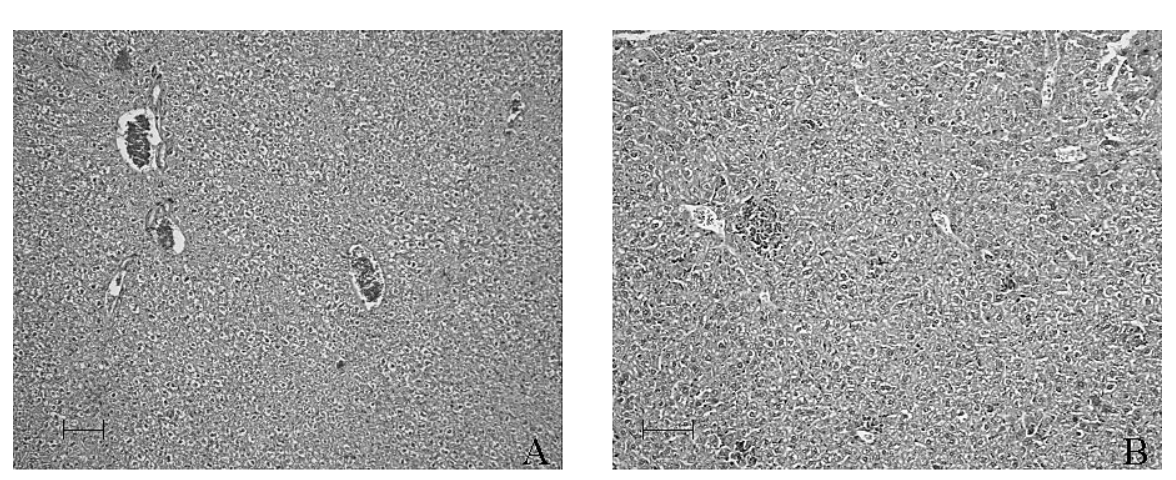
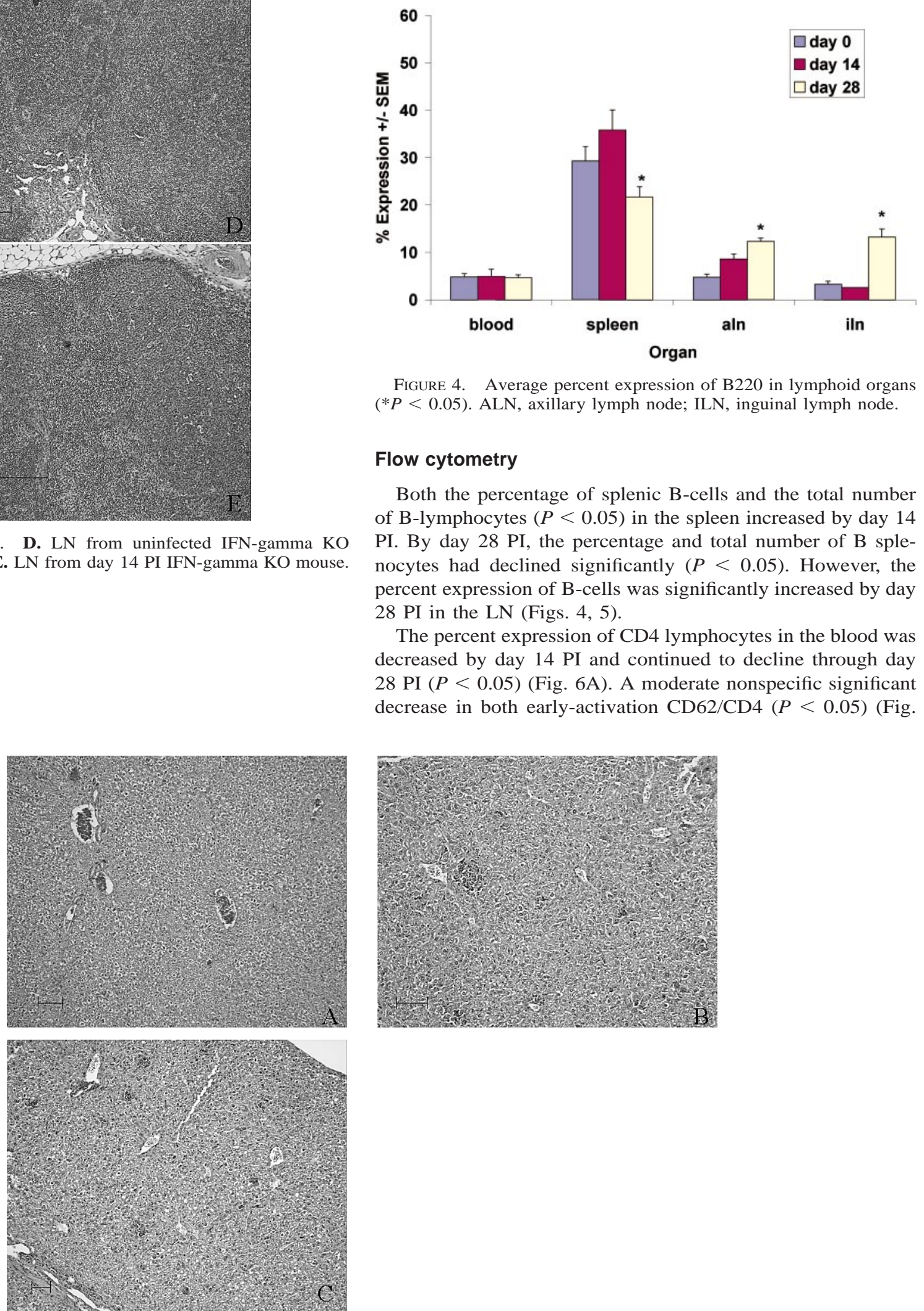

FIGURE 4. Average percent expression of B220 in lymphoid organs $(* P<0.05)$. ALN, axillary lymph node; ILN, inguinal lymph node

\section{Flow cytometry}

Both the percentage of splenic B-cells and the total number of B-lymphocytes $(P<0.05)$ in the spleen increased by day 14 PI. By day 28 PI, the percentage and total number of B splenocytes had declined significantly $(P<0.05)$. However, the percent expression of B-cells was significantly increased by day 28 PI in the LN (Figs. 4, 5).

The percent expression of CD4 lymphocytes in the blood was decreased by day 14 PI and continued to decline through day 28 PI $(P<0.05)$ (Fig. 6A). A moderate nonspecific significant decrease in both early-activation CD62/CD4 $(P<0.05)$ (Fig.

FIgURE 3. Histopathologic changes of the liver associated with Sarcocystis neurona infection in IFN-gamma KO mice. A. Liver from uninfected control mouse. Bar $=100 \mu \mathrm{m}$. B. Infected liver on day 14 PI from IFN-gamma KO mouse. Bar $=80 \mu \mathrm{m}$. C. Infected liver on day 28 PI from IFN-gamma KO mouse. Bar $=50 \mu \mathrm{m}$. 


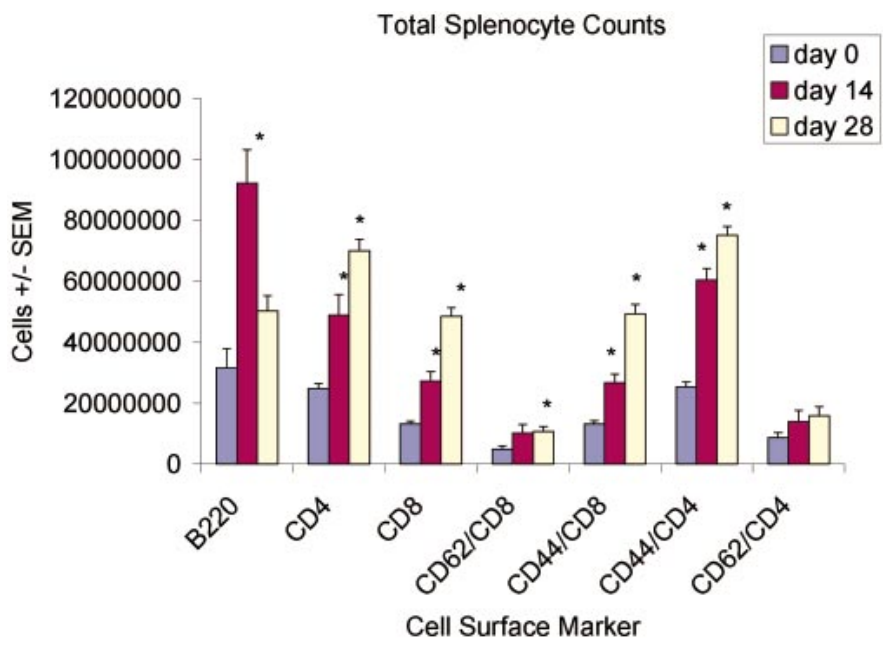

FIGURE 5. Total splenocyte counts from uninfected and Sarcocystis neurona-infected IFN-gamma KO mice $(* P<0.05)$.

6B) and memory CD44/CD4 $(P=0.06)$ (Fig. 6C) peripheral blood lymphocytes on day 14 and day 28 PI was observed. There was also a significant decrease in the percentage of CD4 cells that were $\mathrm{CD}_{2}{ }^{+}$at both time points (data not shown). In the spleen, the percentage of CD4 lymphocytes was marginally decreased on day 14 PI, but by day 28 the percentage became significantly increased. Total number of CD4 splenocytes was significantly increased on day 14 PI and remained persistently elevated on day 28 PI. There were no significant changes in the percentage of CD62/CD4 lymphocytes present, and there was only a mild nonsignificant increase in total CD62/CD4 splenocytes on day 28 PI. There was mild downregulation of CD62/ CD4, based on the percentage of CD4 cells that were CD62+ (data not shown). There was a nonsignificant increase in the percentage of CD44/CD4 splenocytes on day $28 \mathrm{PI}$ as well as a significant increase in the total number of CD44/CD4 splenocytes on days 14 and 28 PI. In the ALN, there was a mild significant decrease in CD4 lymphocytes by day 28 PI. There was little change in the early-activation CD62/CD4 subset, but there was a marked significant increase in the CD44/CD4 subset on day 14 PI, which then diminished by day 28 PI. In the ILN, there was no significant change in CD62/CD4 lymphocytes. In contrast to the ALN, in the ILN there was a nonsignificant decrease in the percentage of CD44/CD4 lymphocytes on day $14 \mathrm{PI}$, which returned to similar levels as that of control mice by day 28 PI.

The percentage of peripheral blood CD8 lymphocytes increased significantly by day 14 PI and then declined slightly by day 28 PI but was still significantly greater than the controls (Fig. 7A). The percentage of CD62/CD8 lymphocytes did not change (Fig. 7B), but there was a marked significant decrease in the percentage of CD8 cells that were CD62 $2^{+}$(Fig. 7C). This was coupled with a significant increase in the percentage of CD44/CD8 lymphocytes on day 14 PI.

In the spleen, the total number of CD8 splenocytes had increased significantly by day 14 PI and continued to increase through day 28 PI. However, the percentage of overall CD8 splenocytes did not increase significantly until day 28 PI. There was mild downregulation of CD8 splenocytes that were CD62+ on day 14 PI (Fig. 7C). More importantly, the total number of

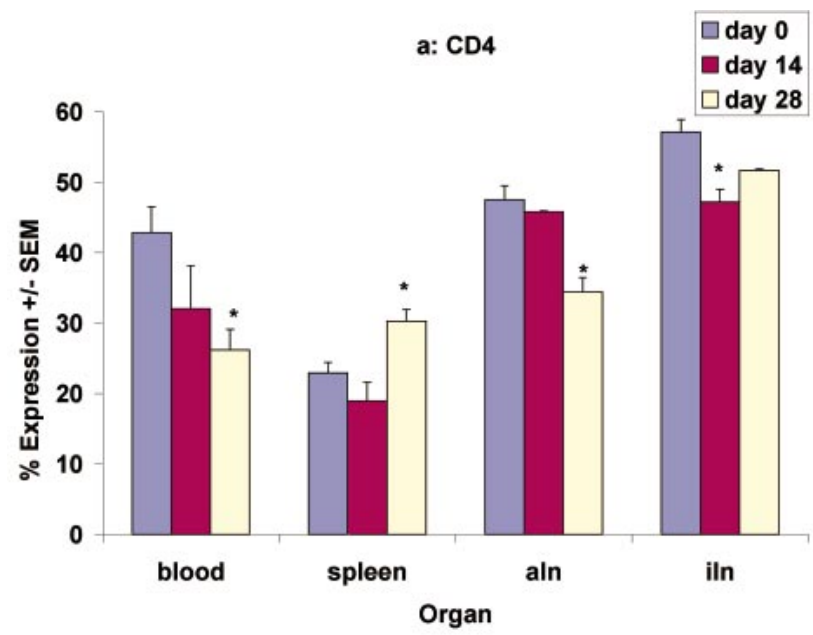

b: $\mathrm{CD} 62 / \mathrm{CD} 4$

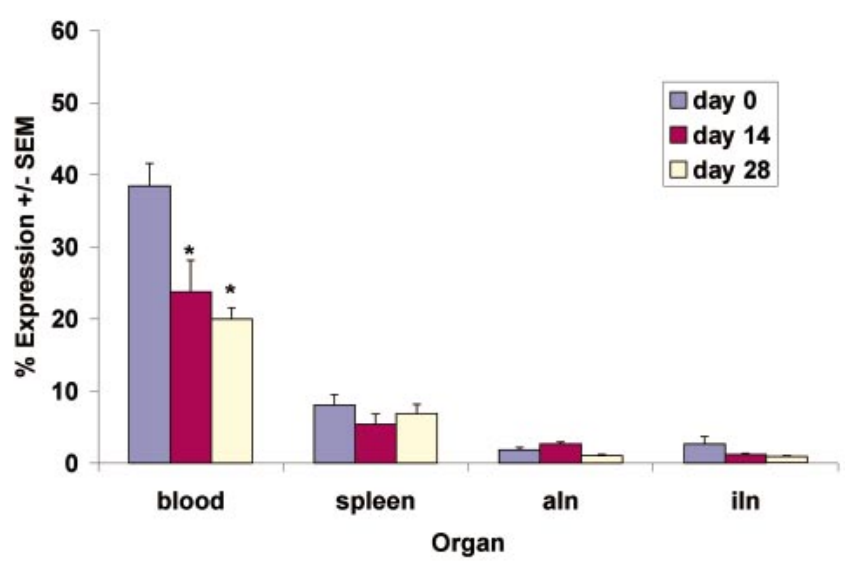

c: CD44/CD4

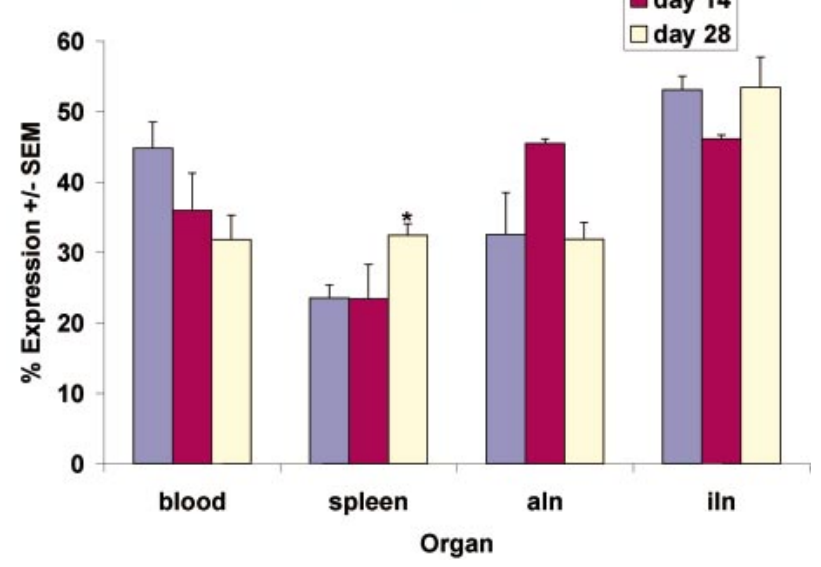

FIGURE 6. Average percent expression of CD4 in lymphoid organs $(* P<0.05)$. A. Average percent expression of CD4 in lymphoid organs. B. Average percent expression of CD62/CD4 in lymphoid organs. C. Average percent expression of CD44/CD4 in lymphoid organs. 


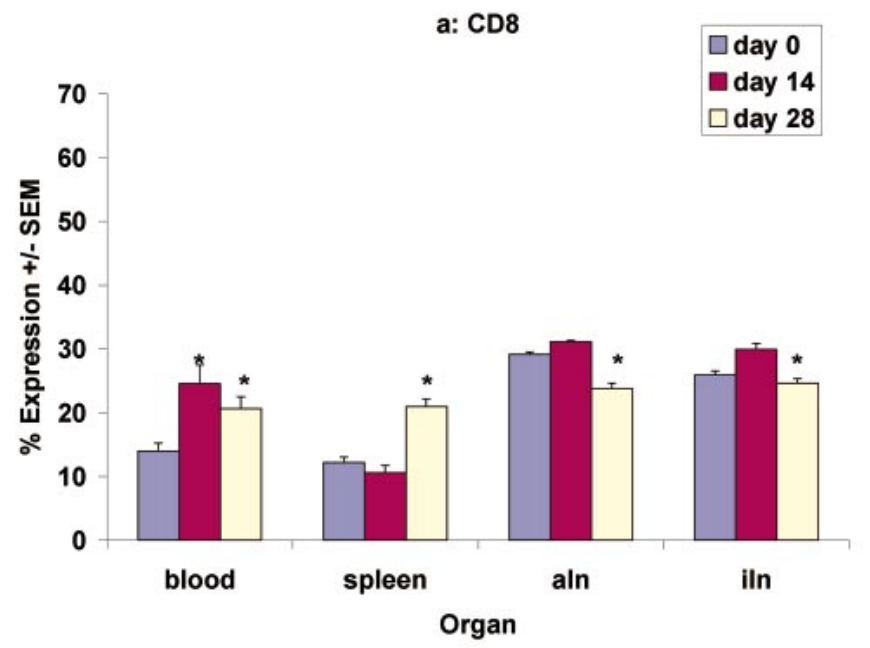

c: Percent CD8 Cells that are CD62+

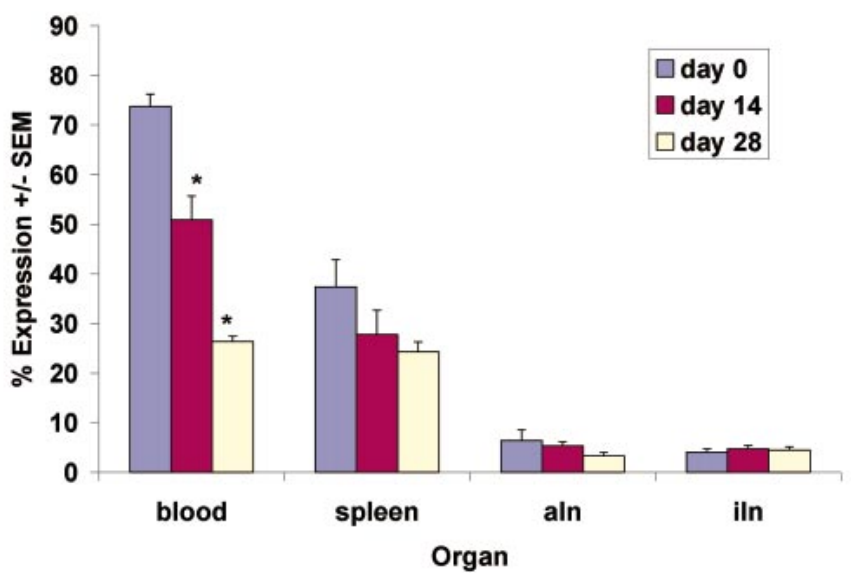

b: CD62/CD8

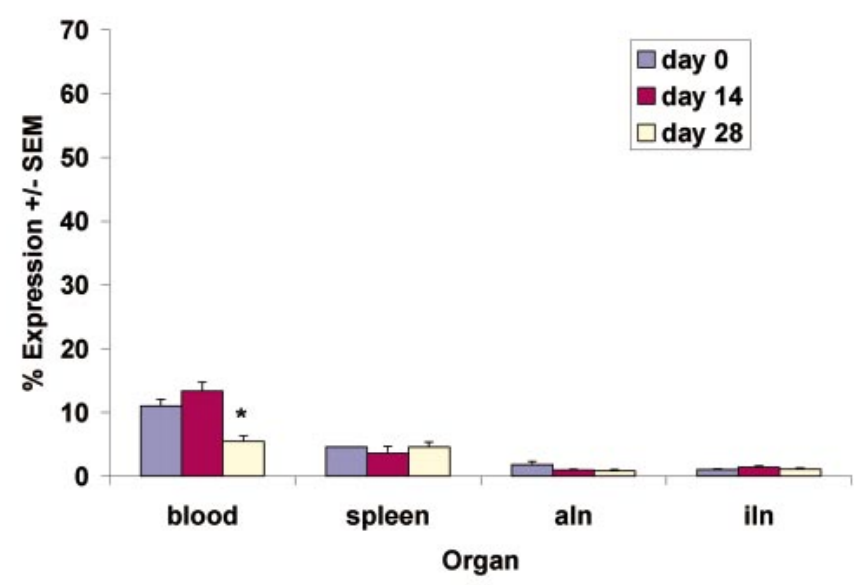

d: CD44/CD8

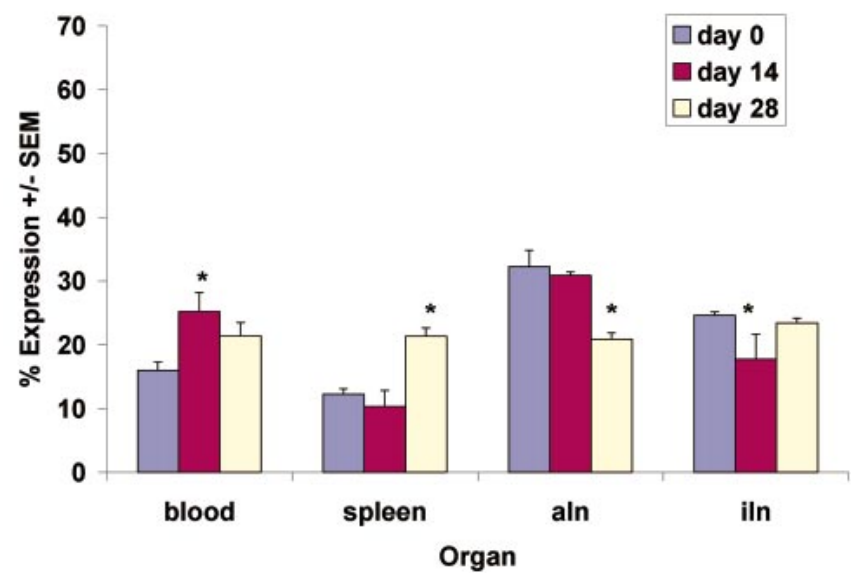

FiguRE 7. Average percent expression of CD8 in lymphoid organs $(* P<0.05)$. A. Average percent expression of CD8. B. Average percent expression of CD62/CD8. C. Average percent expression of CD8 lymphocytes that are CD62 + . D. Average percent expression of CD44/CD8.

CD44/CD8 splenocytes was significantly increased on both day 14 and day $28 \mathrm{PI}$; the percentage of memory splenocytes that were CD44/CD8 significantly increased by day 28 PI.

In the ALN, there was a mild significant decrease in CD8 lymphocytes on day 28 PI, associated with a significant decrease in both the percentage of CD44/CD8 lymphocytes and the percentage of CD8 lymphocytes that were CD44+ (data not shown). In the ILN, there were mild insignificant changes in the percentage of CD8 lymphocytes present. The percentage of CD62/CD8 lymphocytes did not change significantly, and there was a mild decrease in CD44/CD8 lymphocytes on day $14 \mathrm{PI}$, which normalized on day $28 \mathrm{PI}$.

\section{DISCUSSION}

As has been previously described (Dubey and Lindsay, 1998; Fritz and Dubey, 2002), IFN-gamma KO mice infected with $S$. neurona develop terminal encephalitis. Previous studies have focused on parasite life cycle, pathology, and response to treatment. In the present study, we have focused on the pathoimmunology associated with infection. Sarcocystis neurona-in- fected mice developed splenomegaly with increased EMH and bilateral symmetrical lymphadenopathy by day 14 PI. Hepatic changes included mixed inflammatory foci and perivascular lesions. The latter were also present in the lungs, accompanied by interstitial pneumonia.

Although the mice developed encephalitis, multiple organs were affected. As S. neurona exists intracellularly (Fritz and Dubey, 2002), it is possible that other types of cells and organs are infected. Both in mice and other species, i.e., cats, raccoons, $S$. neurona can cause lesions in many tissues, including muscle, heart, lung, liver, intestine, and retina (Hamir and Dubey, 2001; Dubey, 2001a, b; Fritz and Dubey, 2002). In addition, others have shown through immunohistochemistry that $S$. neurona has been identified in only some of these lesions (Dubey, 2001b). Therefore, the pathophysiology of these changes has not been ascertained. Several possible hypotheses have been proposed. Some damage may have been directly due to $S$. neurona infection. Alternatively, the subsequent host immune and inflammatory response may have caused lesions in an attempt to clear the infection. The last hypothesis is that 
secondary infections may have developed in the already infected immunocompromised host. The latter appears to be less likely based on the negative serology for common pathogens and the high prevalence of the changes.

Because S. neurona is an intracellular pathogen of leukocytes and other cells including monocytes and endothelial cells (Dubey, 2001b; Fritz and Dubey, 2002), it is more likely that the interstitial pneumonia and perivascular reactions were either a primary result of $S$. neurona infection or due to inflammatory response associated with infection. Inflammatory foci have been reported in other infectious disease models, i.e., gamma herpes virus, that are associated with immune-mediated clearance of infected cells (Belz et al., 1998; Marshall et al., 2001). We propose that this is one possible mechanism for the focal lesions. This cannot be confirmed without immunohistochemical analysis of the lesions. In addition, increased EMH is also commonly seen associated with infectious diseases (Prunescu, 1999); thus, its presence is likely secondary to the immune and inflammatory response rather than a direct consequence of $S$. neurona itself. Finally, as has been reported previously in horses and mice, infected animals also develop perivascular lesions in multiple organs including the brain, liver, and lungs (Rooney et al., 1970; Daft et al., 2002; Fritz and Dubey, 2002). The explanation for this observation is not clear, but we propose that because $S$. neurona can exist intracellularly in leukocytes and endothelial cells, it is plausible that S. neurona-infected cells stimulate localized inflammation that results in perivascular inflammation. It would seem plausible that $S$. neuronainfected cells may penetrate the endothelium or epithelium in already inflamed areas, leading to infection within that specific organ. The result may be focal liver lesions, myositis, pneumonia, penetration of the blood-brain barrier (BBB), and encephalitis. Toxoplasma gondii can penetrate epithelium and endothelium as well as monocytic and lymphocytic cells (Morisaki et al., 1995; Brunton et al., 2000; Barragan and Sibley, 2002). Infected monocytes can then penetrate the BBB (Huang and Jong, 2001). In addition, another proposed mechanism by which $T$. gondii penetrates the BBB involves transcellular migration of the endothelial cells, which may be mediated by SAG-1, or SAG-3, or both (Morisaki et al., 1995; Huang and Jong, 2001; Barragan and Sibley, 2002). It appears plausible that $S$. neurona may also be able to penetrate the BBB through either infected leukocytes or transcellular migration.

To this point, the immune response associated with $S$. neurona infection in gamma-IFN KO mice had not been defined. Changes in the spleens and LN demonstrated a marked and seemingly "appropriate" response to infection based on increased follicular activity on day 14 PI. However, on day 28 PI, follicles in the spleen and LN have a "wasted, burnt out" appearance. EMH predominates because of the loss of lymphocytes and increased cellularity in the regions outside the follicles and germinal centers. In immunocompetent C57BL/6 (B6) mice, clearance of the infection was correlated with resolution of follicular activity and EMH in the spleens and LN (Witonsky et al., 2003a).

Humoral response to $S$. neurona in IFN-gamma-infected mice consisted of an early and marked increase in B-cells in the spleen and ALN, with a marked significant increase in total splenic B-cell numbers. However, the response was not sustained as both the percentage of B-cells decreased below that of uninfected mice, and the total number of B-cells in the spleen decreased dramatically on day 28 PI. The marked decline in Bcell percentages to less than that of the uninfected mice, combined with the progressive histologic changes, i.e., in spleen, liver, lung, suggest the inability to respond to and control the infection.

Analysis of the cell-mediated response showed an acute nonsubset-specific loss in the percentage of CD4 lymphocytes in the spleen and blood on day 14 PI. In the peripheral blood, the decreased percentage was at least partially offset because of the increased percentage of CD8 lymphocytes. In the spleen, there was an increase in B-cells that would also partially offset the percentage of CD4 lymphocytes. Loss of CD4 cells due to infection was also possible. On day $28 \mathrm{PI}$, the percentage of CD4 splenocytes increased significantly. This was partly due to the loss of B-cells. It was also likely due to antigen stimulation, based on the increased total number of CD4 splenocytes. Despite changes in immune cell subsets, the total number of CD4 splenocytes increased significantly and dramatically on day 14 PI and continued to increase through day 28 PI. It was the memory CD44/CD4 subset that was affected $(P<0.05)$.

Analysis of the CD8 subset showed similar response to the CD4 subset in the spleen. By day 14 PI, there was a significant increase in CD8 expression in the blood, and the percentage of CD8 expression in the spleen did not increase significantly until day 28 PI. However, total CD8 splenocytes increased significantly by day 14 PI and continued to increase through day 28 PI. In the blood and the spleen, the changes in CD8 population appeared to be due to downregulation of the early-activation CD62/CD8 population combined with significant $(P<0.05)$ upregulation of the CD44/CD8 subset. Total splenocytes reflected this change as well. There was a slight, nonsignificant increase in total number of CD62/CD8 lymphocytes on day 14 PI, which became significantly increased on day 28 PI, whereas the CD44/CD8 lymphocytes continued to increase significantly from day 14 PI through day 28 PI $(P<0.05)$. Changes in percentage of CD8 expression in the ALN and ILN were mild, although there was a significant decrease $(P<0.05)$ in CD44/ CD8 expression on days 14 and 28 PI, respectively. This may have been due to the inability to sustain this level of immune response. Overall, the sustained increase in CD4 and CD8 splenocytes of predominantly the memory subset, combined with histopathologic progression and the inability to sustain the humoral responses, suggests continued immunological stimulation due to the lack of resolution of the infection.

The persistence of infection was supported by flow cytometric changes. In immunocompetent $\mathrm{B} 6$ mice, the protective immune response associated with $S$. neurona infection, based on the time points examined, consisted of a marked and sustained increase in B-cell numbers through day $28 \mathrm{PI}$ as well as a marked increase in CD8 populations (Witonsky et al., 2003a). The cell-mediated protective response appeared to be mediated by the CD8 population, based on the downregulation of CD62/ CD8 lymphocytes with the more significant upregulation of CD44/CD8 lymphocytes based on total numbers and percentages $(P<0.05)$. The peak response in the C57BL/6 mice, based on the time points examined, occurred on day 14 PI, and by day $28 \mathrm{PI}$, there was a decrease in the total number of CD8 cells as well as CD44/CD8 lymphocytes, suggestive of resolu- 
tion of infection. Histopathologic analysis also supported resolution of infection.

In the IFN-gamma KO mice infected with $S$. neurona, the humoral response becomes exhausted because of the inability of the cell-mediated immune response to clear the infection. As has been shown with $T$. gondii and has been demonstrated in S. neurona-infected C57BL/6 mice, the CMI response was most critical for protection. In $T$. gondii infections, humoral immunity was supportive in the acute response, and it serves a more critical role in chronic infections. However, both CD4 and CD8 responses were critical for CMI. It was predominantly IFN-gamma, produced by CD4 and CD8 cells, which mediates the protective effect. Further, Gazzinelli et al. (1992) demonstrated that although both populations were critical, CD8-mediated immune response was more important.

Comparing the CMI response, both C57BL/6 and IFN-gamma KO mice exhibited a non-subset-specific loss of CD4 lymphocytes in multiple lymphoid organs. In the C57BL/6 mice, total number of CD4 splenocytes was increased by day 14 PI but returned to "control" levels by day 28 PI because the infection was resolving infection. In the IFN-gamma KO mice, the CD4, particularly the memory CD44/CD4 response, was sustained.

Comparison of CD8 populations between C57BL/6 and IFNgamma $\mathrm{KO}$ mice revealed an early acute increase in the percentage of CD8 cells in the blood and a delayed increase in the spleen on day $28 \mathrm{PI}$ in IFN-gamma KO mice. The naive CD62/ CD8 subset was downregulated in multiple organs with upregulation of the memory CD44/CD8 response. Changes in subset analysis were similar. Again, these changes were seen in C57BL/6 mice but occurred more rapidly in the C57BL/6 mice than in the IFN-gamma $\mathrm{KO}$ mice. In addition, the memory response was resolving on day $28 \mathrm{PI}$ in the C57BL/6 mice, whereas the $\mathrm{CD} 8$ response in IFN-gamma $\mathrm{KO}$ mice continued to be sustained because of chronic infection, as evidenced by histological changes, including the presence of $S$. neurona merozoites in the central nervous system.

To summarize, in IFN-gamma KO mice infected with $S$. neurona, neither $\mathrm{CD}^{+}{ }^{+}$nor $\mathrm{CD}^{+}$lymphocytes were completely functional. Not only does the absence of IFN-gamma affect Tcell function, but, as stated previously, IFN-gamma also affects both innate (i.e., NK, macrophage) and acquired (i.e., lymphocyte) responses, which alter the normal host immune response. As a result, $S$. neurona was not cleared, and antigenic stimulation remained, causing continued CD4, CD8, and B-cell proliferation and recruitment. Eventually, B-cell exhaustion occurred, and by day $28 \mathrm{PI}$, because of the inability to clear infection, S. neurona had already penetrated the BBB, resulting in terminal encephalitis or meningoencephalitis.

\section{ACKNOWLEDGMENTS}

We thank Dan Ward for the statistical analysis. This research was supported by a Cooperative State Research, Education, and Extension Service Animal Health and Disease grant to S.G.W, D.S.L, and R.M.G.

\section{LITERATURE CITED}

Barragan, A., And L. Sibley. 2002. Transepithelial migration of Toxoplasma gondii is linked to parasite motility and virulence. Journal of Experimental Medicine 195: 1625-1633.

Belz, G., J. Altman, and P. Doherty. 1998. Characteristics of virus specific CD8 $+\mathrm{T}$ cells in the liver during the control and resolution phases of influenza pneumonia. Proceedings of the National Academy of Sciences 95: 13812-13817.

Brunton, S., G. Wallace, E. Graham, and M. Stanford. 2000. The effects of cytokines on the replication of $T$. gondii within rat retinal vascular endothelial cells. Journal of Neuroimmunology 102: 182188.

Cutler, T., R. Mackay, P. Ginn, K. Gillis, S. Tanhauser, E LeRay, J. DARne, AND E. GReInER. 2001. Immunoconversion against Sarcocystis neurona in normal and dexamethasone treated horses challenged with Sarcocystis neurona. Veterinary Parasitology 95: 197210 .

Daft, B. , B. Barr, I. Gardner, D. Read, W. Bell, K. Peyser, A. Ardans, H. Kinde, AND J. Morrow. 2002. Sensitivity and specificity of western blot testing of cerebrospinal fluid and serum for diagnosis of equine protozoal myeloencephalitis in horses with and without neurologic abnormalities. Journal of the American Veterinary Medical Association 221: 1007-1013.

Dubey, J. P. 2001a. Parasitemia and early tissue localization of Sarcocystis neurona in gamma-interferon knock-out mice fed sporocysts. Journal of Parasitology 8: 1476-1479.

- 2001b. Migration and development of Sarcocystis neurona in tissues in interferon-gamma knockout mice fed sporocysts from a naturally infected opossum. Veterinary Parasitology 95: 341-351.

, AND D. S. LiNDSAY. 1998. Isolation in immunodeficient mice of Sarcocystis neurona from opposum (Didelphis virginiana) faeces and its differentiation from Sarcocystis falcatula. International Journal for Parasitology 28: 1823-1828.

Fenger, C., D. Granstrom, A. Gajadhar, N. Williams, S. McCrillis, S. Stamper, J. Longemeier, AND J. P. Dubey. 1997. Experimental induction of equine protozoal myeloencephalitis in horses using Sarcocystis $s p$. sporocysts from the opossum (Didelphis virginiana). Veterinary Parasitology 68: 199-213.

FritZ, D., AND J. P. DubeY. 2002. Pathology of Sarcocystis neurona in gamma-interferon knock-out mice. Veterinary Pathology 39: 137140.

Gazzinelli, R., Y. Xu, S. Hieny, A. Cheever, And A. Sher. 1992. Simulataneous depletion of CD4+ and CD8 $+\mathrm{T}$ lymphocytes is required to reactivate chronic infection with Toxoplasma gondii. Journal of Immunology 149: 175-180.

Gogal, R., M. Prater, M. Johnson, and S. Holladay. 2000. Bilateral sections of spleen and thymus in rodents exhibit homogeneity in leukocyte marker expression. Toxicology 157: 217-223.

HamiR, A. N., AND J. P. Dubey. 2001. Myocarditis and encephalitis associated with Sarcocystis neurona infection in raccoons (Procyon lotor). Veterinary Parasitology 95: 335-340.

HuANG, S., AND A. Jong. 2001. Cellular mechanisms of microbial proteins contributing to invasion of the blood brain barrier. Cellular Microbiology 3: 277-287.

LindSAY, D. S., AND J. P. DubEY. 1999. Determination of the activity of pyrimethamine, trimethoprim, sulfonamides, and combinations of pyrimethamine and sulfonamides against Sarcocystis neurona in cell cultures. Veterinary Parasitology 82: 205-210.

- AND — 2001. Direct agglutination test for the detection of antibodies to Sarcocystis neurona in experimentally infected animals. Veterinary Parasitology 95: 179-186.

MACKAY, R. 1997. Equine protozoal myeloencephalitis. Veterinary Clinics of North America: Equine Practice 13: 79-96.

Marsh, A., B. Barr, J. Lakritz, R. Norhausen, J. Madigna, and P. CONRAD. 1997. Experimental infection of nude mice as a model for Sarcocystis neurona-associated encephalitis. Parasitology Research 83: 706-711.

Marshall, D., S. Turner, G. Belz, S. Wingo, S. Andreansky, M. SAngster, J. Riberdy, T. LiU, AND P. Doherty. 2001. Measuring diaspora for virus specific CD8 $+\mathrm{T}$ cells. Proceedings of the National Academy of Sciences 98: 6313-6318.

MorisAKi, J., J. Heuser, AND L. Sibley. 1995. Invasion of Toxoplasma gondii occurs by active penetration of the host cell. Journal of Cell Science 108: 2457-2464.

PRUNESCU, P. 1999. Hepatic hematopoiesis in adult mouse during experimental rodent malaria. Roum Archives of Microbiological Immunology 58: 79-94. 
Rooney, J., M. Prickett, and F. Delaney. 1970. Focal myelitis-encephalitis in horses. Cornell Veterinarian 60: 494-499.

Rosypal, A. C., D. S. Lindsay, R. B. Duncan, S. A. Ahmed, A. M. ZaJAC, AND J. P. Dubey. 2002. Mice lacking the gene for inducible or endothelial nitric oxide are resistant to sporocyst induced Sarcocystis neurona infections. Veterinary Parasitology 103: 315-321.

Saville, W., S. Reed, D. Granstrom, K. Hichcliff, C. Kohn, T. WitTUM, AND S. STAMPER. 1997. Prevalence of serum antibodies to $S$. neurona in horses in Ohio. Journal of the American Veterinary Medical Association 210: 519-524.

, R. Stich, S. Reed, C. Nuoku, M. Oglesbeer, A. Nunschmann, D. Grover, A. Larew-Naugle, J. StaneK, D. Granstrom, and J.
DUBEY. 2001. Utilization of stress in the development of an equine model for equine protozoal myeloencephalitis. Veterinary Parasitology 95: 211-222.

Tripp, R., A. Hamilton-Easton, P. Cardin, P. Nguyen, F. Behm, S. Woodland, P. Doherty, and M. Blackman. 1997. Pathogenesis of an infectious mononucleosis-like disease induced by a murine gamma-herpes virus: Role for a viral superantigen? Journal of Experimental Medicine 185: 1641-1650.

Witonsky, S., R. M. Gogal, R. B. Duncan, and D. S. Lindsay. 2003a. Protective immune response to experimental infection with Sar cocystis neurona in C57BL/6 mice. Journal of Parasitology 89. 924-931. 